\title{
EXPLORATION OF CONTINIOUS LEARNING AND ITS PROMINENCE
}

\author{
S. M. Karthikeyan \\ Research Scholar, College of management, SRM Institute of Science and Technology, \\ Kattankulathur, Tamil Nadu, India
}

\begin{abstract}
V M Ponniah
Dean, College of management, SRM Institute of Science and Technology, Kattankulathur, Tamil Nadu, India
\end{abstract}

\begin{abstract}
P.S. Rajeswari
Associate Professor, College of management, SRM Institute of Science and Technology, Kattankulathur, Tamil Nadu, India
\end{abstract}

\begin{abstract}
Every corner of the world was shaken due to the COVID-19 pandemic, one of the greatest calamities of this century. Every country has been taking various measures like quarantines, different phase of lockdowns, social distancing norms, restricted public transport facility, continuous awareness to public, medical camps in different places. Focus of every country is on public health strategies to contain the spread of COVID 19. Normal life was affected all over the world by this pandemic situation. We are moving from lockdown phases to unlock down phases in various places of the country. During this unlock down phases industries were allowed operate with minimum number of employees in the earlier stage and moved to operate $100 \%$ employees now. Number of employees allowed to work was decided by various factors like Government regulations, business requirement, social distancing norms, available space in the factory setup, available machineries in the factory setup to operate in new normal.

Skills learnt by the employees before Covid-19 was very useful to them to receive the first call from their company to work in restricted number of employee's environment. Employees with multi skills are recognised well in this Covid-19 lockdown period and industries were able to manage the customer requirement with minimum number of employees as per Government regulations. All type of organisations realised the importance of learning especially after this pandemic than earlier days.
\end{abstract}

Key words: Covid-19 pandemic, social distancing norms, employees as per Government regulations, this pandemic than earlier days. 
Cite this Article: S. M. Karthikeyan, V M Ponniah and P.S. Rajeswari, Exploration of Continious Learning and Its Prominence, International Journal of Management, 11(12), 2020, pp.1496-1504. http://iaeme.com/Home/issue/IJM?Volume $=11 \&$ Issue $=12$

\section{INTRODUCTION}

Skills learnt by the employees before Covid-19 was very useful to them to receive the first call from their company to work in restricted number of employee's environment. Employees with multi skills are recognised well in this Covid-19 lockdown period and industries were able to manage the customer requirement with minimum number of employees as per Government regulations. All type of organisations realised the importance of learning especially after this pandemic than earlier days

\section{LITERATURE REVIEW}

Various aspects of learning programmes in Automotive industry and latest learning was described in the paper of Rekha Mudkanna and Losarwar S.G. (2014). Also understood that it enables employees to achieve their personal goals and the organisational objectives effectively by learning and adapting new skills, techniques. Learning, Appraisal and Employee involvement had positive impact on employee's performance as specified in the paper of Saria Hassan (2016). Realised the importance of learning for helping employees and their organisation to achieve the win-win situation through research paper by "Shelley Khosla" (2016). Employees can execute their tasks with their skills learnt through the required learning in the organisation. The focus of learning is to facilitate short-term skills and knowledge that allow employees within an organization to efficiently execute their present tasks. Employee will be equipped to accept the additional roles by focusing on development activities on long term goals (Nwokocha, 2015). Productivity can be increased by dynamic human resources in organisation. Enhanced skills and employee commitment also support to increase productivity (Walsh et al., 2010). A study conducted by Bhasker (2013) indicated that auto-ancillary industries are exposed to a crucial challenge with regards to skilled manpower and an innate capability to compete on a global level.

This paper will attempt to identify the importance of learning in automobile industries. Importance of learning is well known by various factors of this study and it has its own influence in the employees to meet the organisational goals.

\section{OBJECTIVE OF THE STUDY}

- To explore the realisation among employees about importance of learning

- To describe the realisation among employers about importance of learning

- To examine the contribution of learning in restricted work environment due to Government rules and regulations of COVID 19

\section{RESEARCH METHODOLOGY}

The prime objective of this research is to study the realisation among employees about importance of learning, the realisation among employers about importance of learning, the contribution of learning in restricted work environment due to Government rules and regulations of COVID 19 and overall development of an employee. The research methodology adopted is basically based on primary data via which the most recent and accurate piece of firsthand information which has been collected. Secondary data has been used to support primary data wherever needed. And the research methods are listed below. 
- Research design

- Sampling design

- Sample size

- Research approach

- Research instrument

- Sample location

- Data type

- Analytical Tools :Pie charts, Bar- graphs etc.

- Sampling unit :Companies in MWC and Oragadam Industrial Parks

- Sampling Area :Chennai
:Exploratory Research

:Convenience Sampling

:30 respondents

:Survey method

: Questionnaire

: Mahindra World City and Oragadam Industrial parks

\section{RESEARCH FINDINGS}

\section{Graph 1: Role of learning in awareness on COVID-19}

All respondents described learning played an important role for awareness of Covid-19 among employees and their friends and families. Only few respondents didn't accept the role of learning.

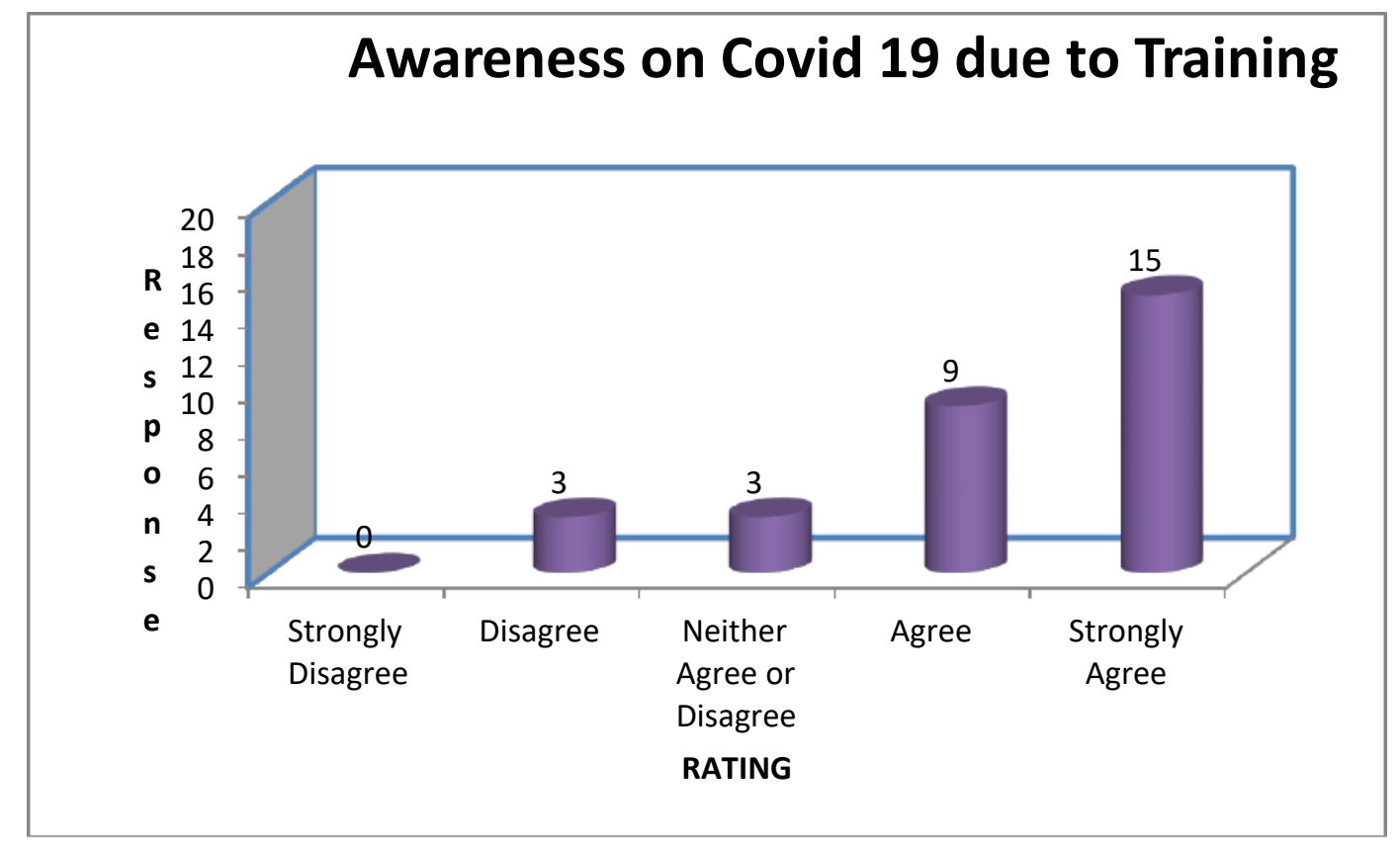

Figure 1

The above Graph (Fig 1) show that 24 respondents agreed the role of learning. Only 3 of our respondents are not accepted the same. 3 of them of neutral in their opinion. It shows the high level of acceptance on learning play a major role in awareness of Covid19.

\section{Graph 2: Minimum impact of COVID 19 due to Learning}

The below Graph (Fig 2) indicated that 27 respondents are accepting the minimum impact is due to Learning. 2 of them expressed their neutral opinion. Only one of the respondent disagreed. 


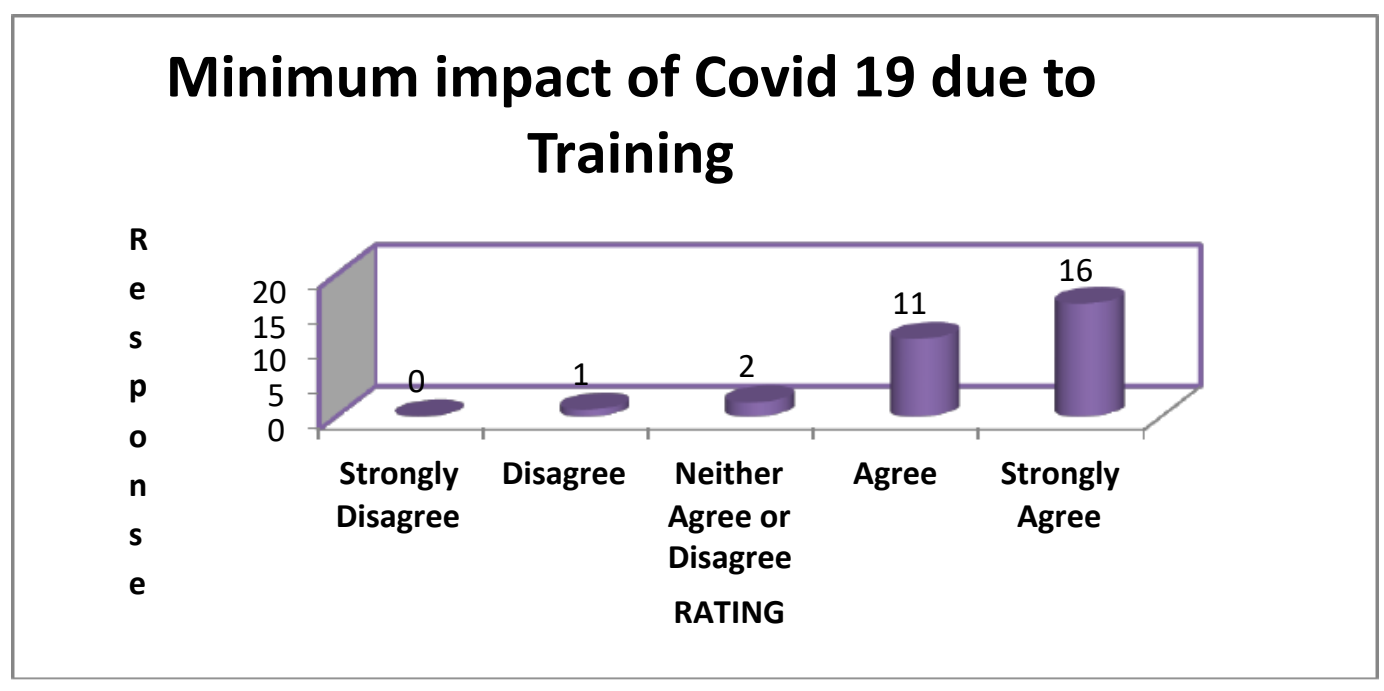

Figure 2

\section{Graph 3: Role of $E$ Learning to meet the learning requirement during COVID-19}

This Graph clearly shows that 26 of our respondents agreed that E Learning helped a lot to meet the learning requirement during COVID 19. 2 of the respondents disagreed. 2 expressed their neutral opinion. Overall, it is understood that contribution of E Learning to meet the learning requirement was remarkable.

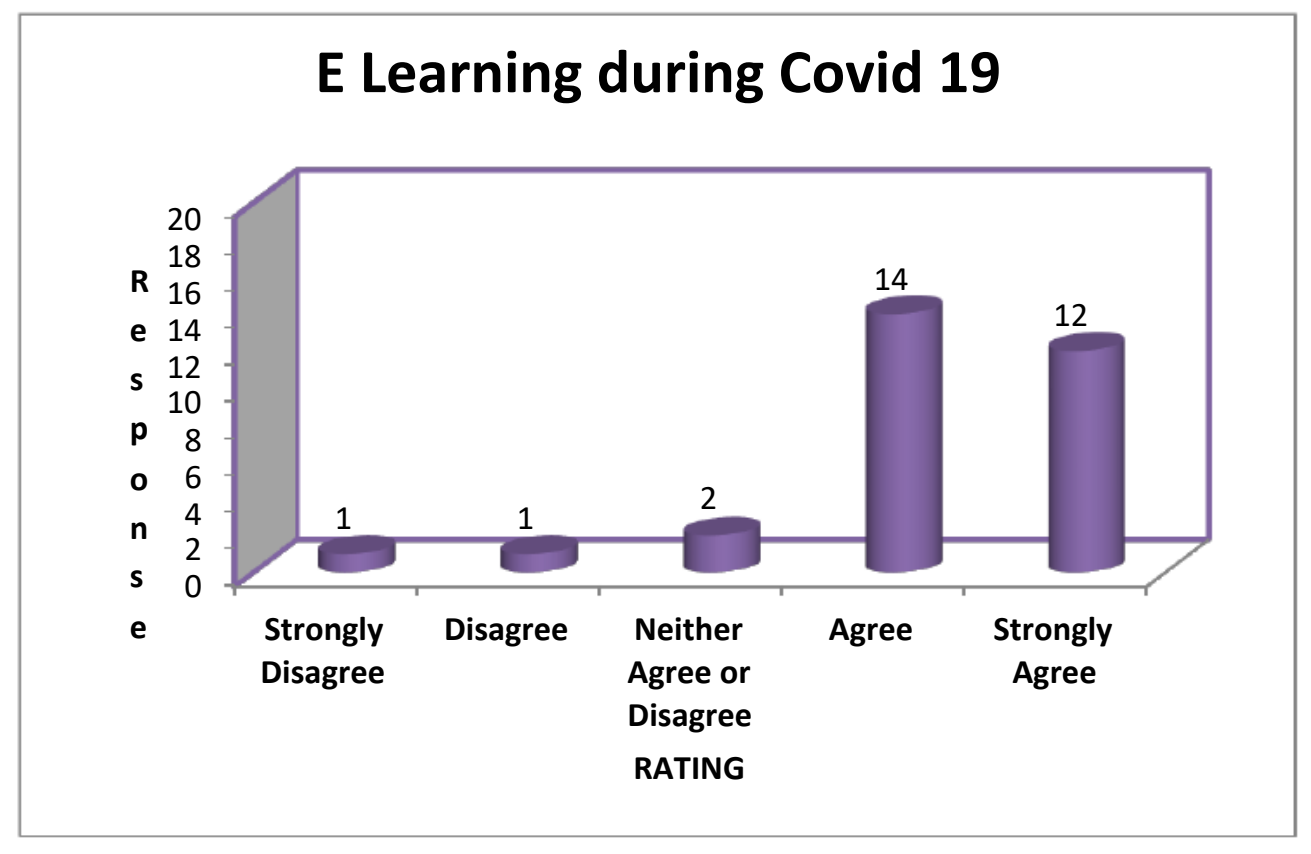

Figure 3

\section{Graph 4: Importance of Learning to be a preferred Employee}

The below Graph (Fig 4) indicated that 25 respondents are accepting the importance of learning to be in the list preferred employees of the organisation. 3 respondents expressed neutral opinion. Only 2 disagreed. Overall learning played a vital role in the career of an employee. 


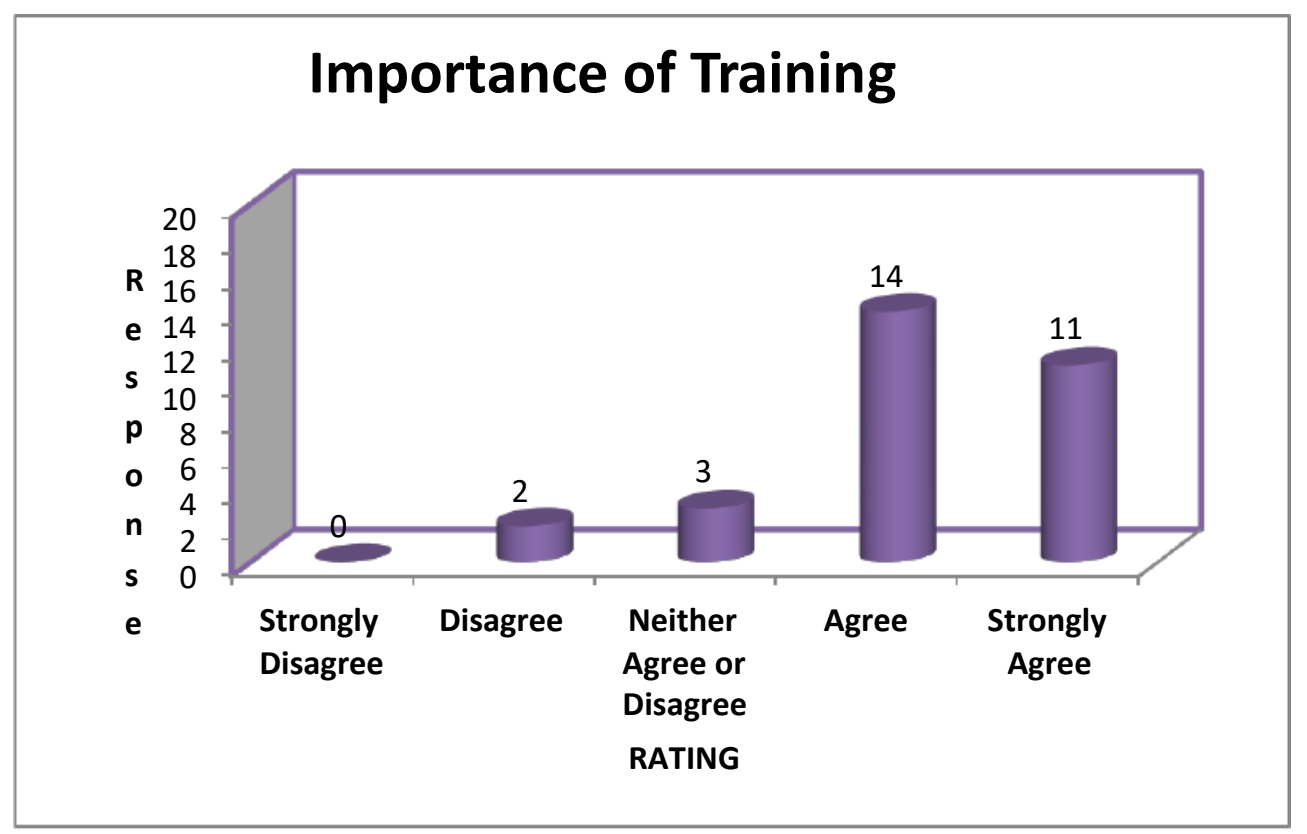

Figure 4

\section{Graph 5: Interest on Learning after COVID-19}

Graph (Fig 5) indicating that 23 of our respondents are accepting their interest on learning has increased after Covid 19. 4 respondents disagreed. 3 was in neutral category. Learning new skills is essential in the VUCA world, so the interest on learning is increasing.

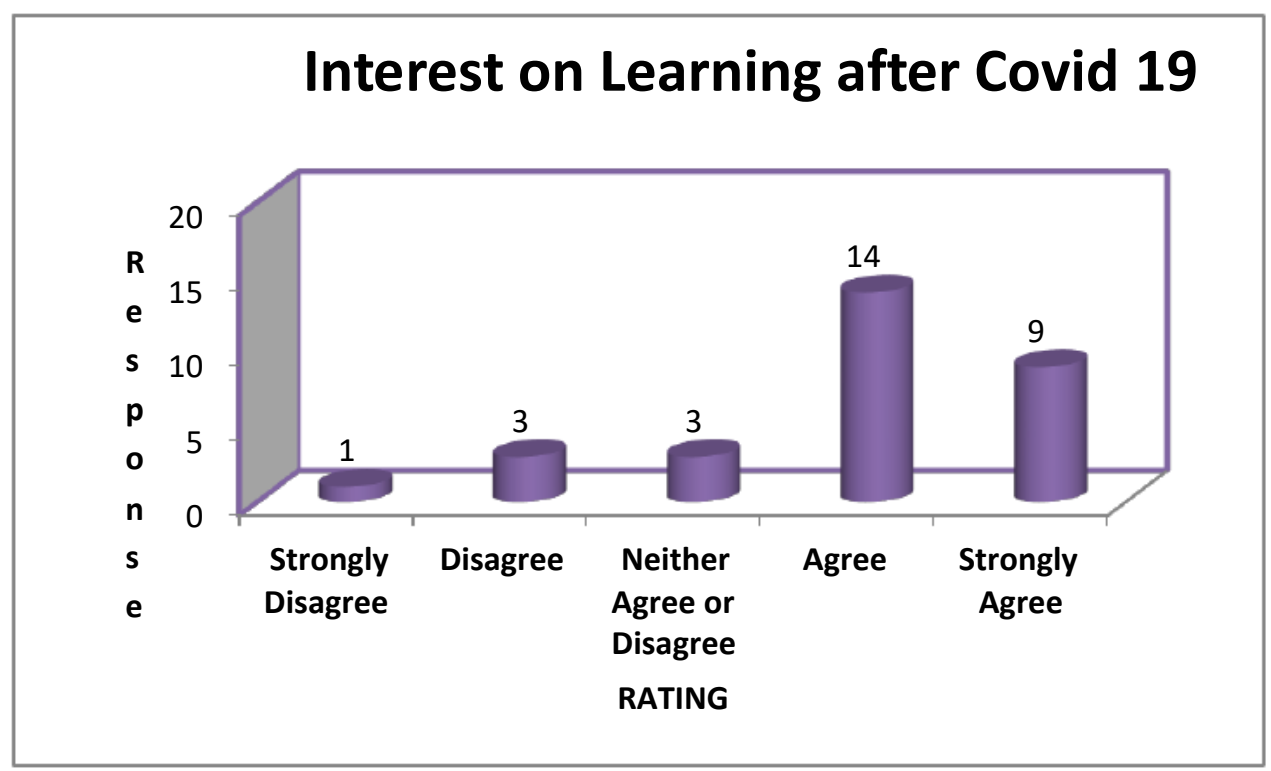

Figure 5 
Graph 6: Importance of Learning for work after COVID-19

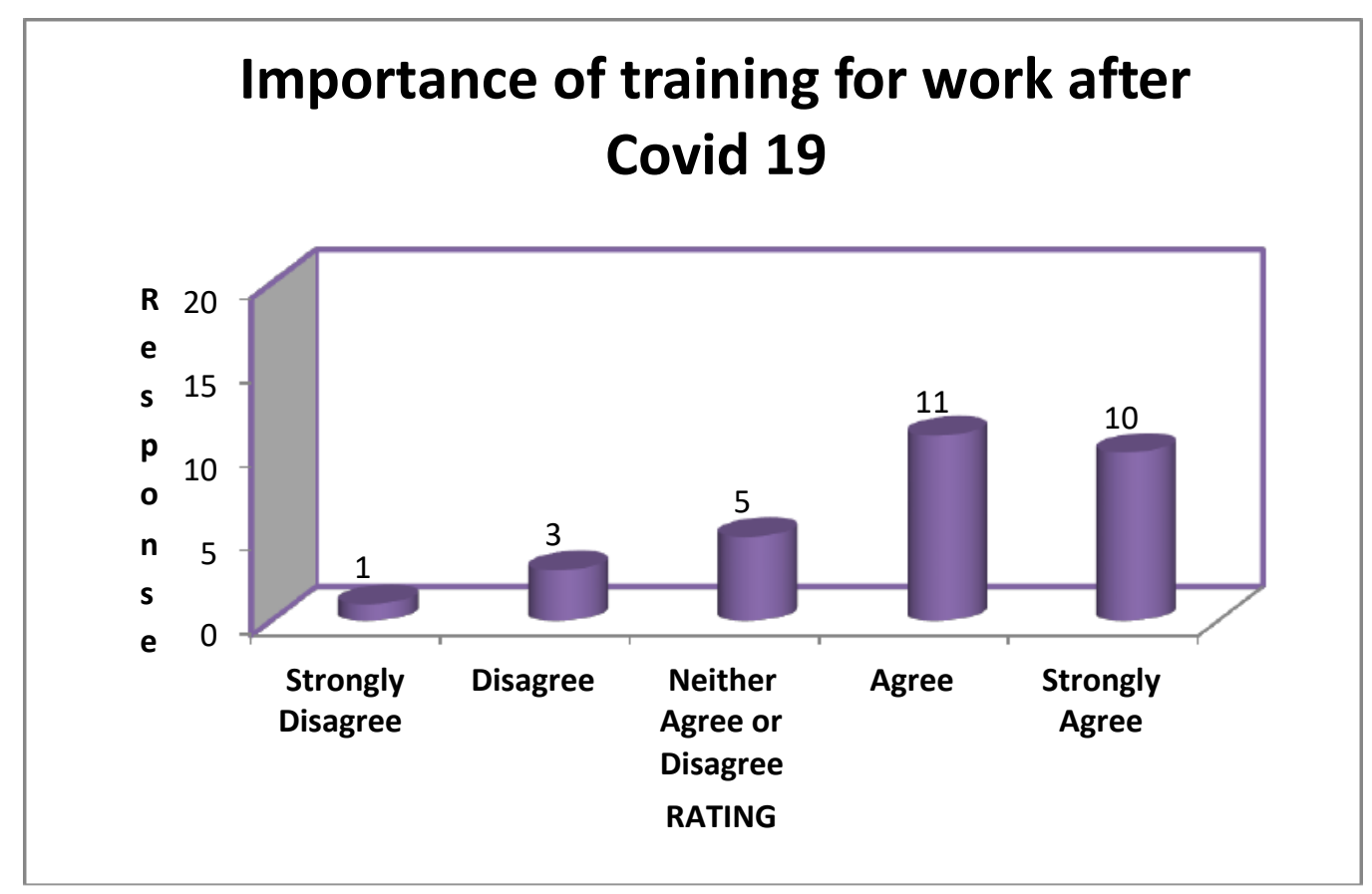

Figure 6

The above Graph (Fig 6) clearly shows the importance of learning for work after COVID 19. 21 respondents are accepting this, 5 in neutral opinion. Only 4 disagreed. From this, we understood that learning plays the vital role to retain the job with multiskills.

\section{Graph 7: Contribution of Learning during unlock down phase of COVID}

We understood from Graph (Fig 7), 23 respondents are accepting the contribution of learning during unlock down phase to meet the production requirement. 5 expressed their neutral opinion. 2 disagreed. Companies could operate with restricted number of employees during unlock down phase. Multi skilled worked got the preference to join first.

\section{Contribution of Training during unlockdown phase of COVID 19}

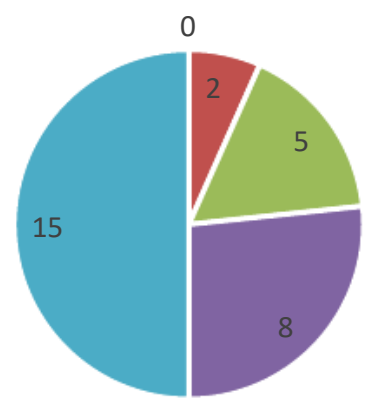

- Strongly Disagree " Disagree " Neither Agree or Disagree - Agree " Strongly Agree

Figure 7 


\section{Graph 8: Importance of Learning to be a preferred Employee}

The below Graph (Fig 8) shows that 22 respondents are accepting that learning is playing the vital role for overall development of employees. 4 expressed neutral opinion. 4 of the respondents disagreed. Learning developing an employee overall.

\section{Effectiveness of Training for overall development of Employees}

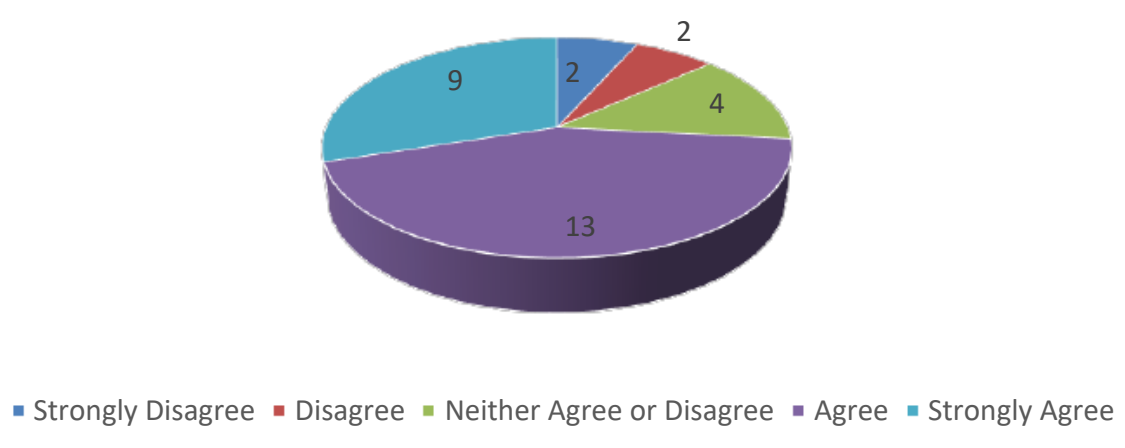

Figure 8

\section{Graph 9: Satisfied with existing Learning methods of Organisation}

This Graph clearly indicates that 22 of our respondents are satisfied with existing methods of organisation. 4 in neutral opinion, 4 of them disagreed. Majority of the respondents are satisfied with the existing learning methods.

\section{Satisfied with existing Training methods in the organisation}

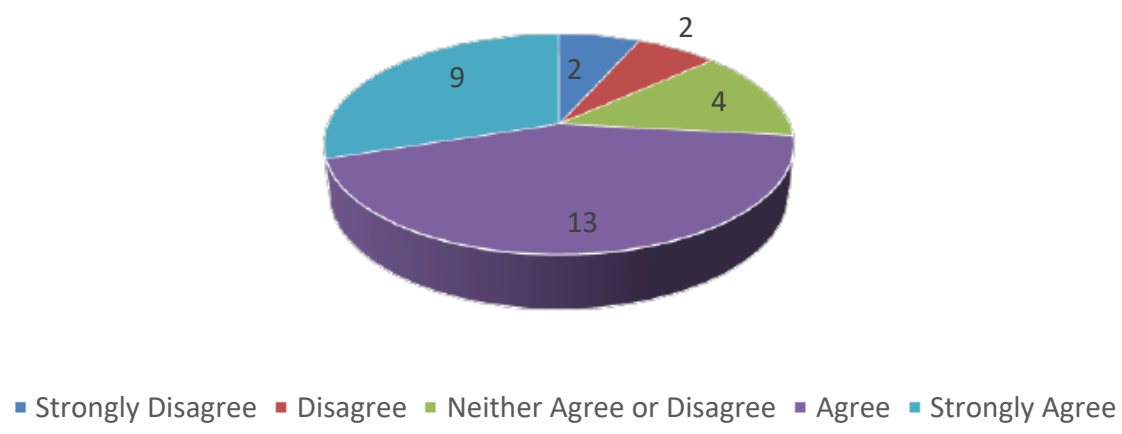

Figure 9

\section{Graph 10: Importance of Learning to be a preferred Employee}

The below Graph (Fig 10) clearly shows that 26 respondents are accepting the importance of learning to improve overall personality in their profession. 2 in neutral, 2 of them disagreed. 
Majority of the respondents agreed that learning improves overall personality for their profession.

\section{Training helps to improve overall personality for profession}

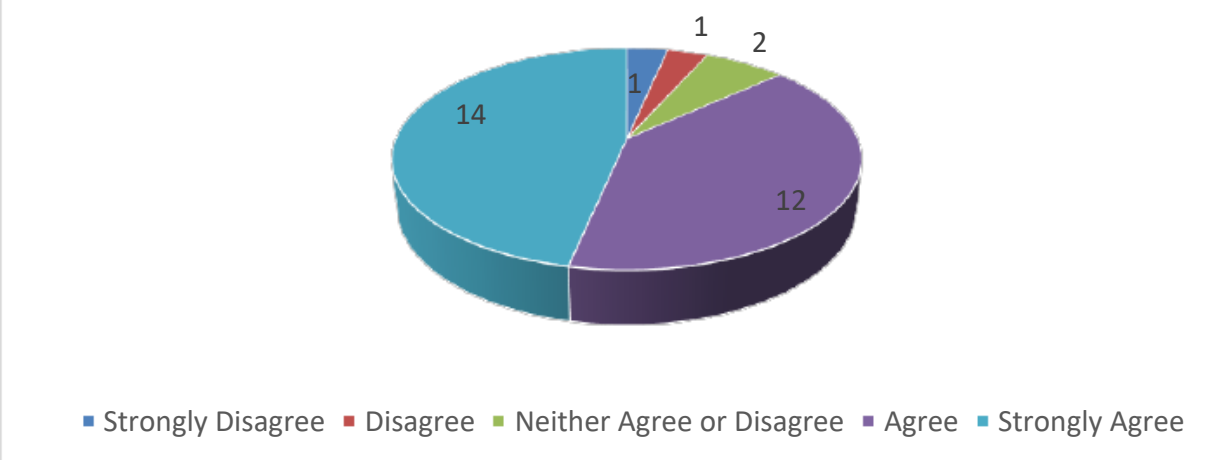

Figure 10

\section{CONCLUSION}

This study found the importance of Learning after COVID-19. Various aspects of importance of learning in terms of awareness, impact, E Learning, interest on learning new skills, role of learning during unlock down phase, contribution to meet the production requirement and contribution to their overall personality in their profession. The data collected from 30 respondents those are working in Automotive industries in Mahindra World City and Oragadam industrial area in Chennai.

Majority of the respondents are understood and accepting that learning is playing a vital role in learning new skills, to be in the list of preferred employees during unlock down phase. During unlock down phase companies could operate with only restricted number employees. So, companies selected the employees with multiskills based on their learning record and gave them first opportunity to meet the production requirement by operating various kind of machines.

In addition to regular classroom learning and on the job learning, E Learning played important role during lockdown phase and unlock down phase. Also, it gives the flexibility to the learner in terms of learning time, swap to interested learning based on the need. Overall, $\mathrm{E}$ Learning contributed a lot to meet the learning needs of every organisation.

Apart from this, majority of the respondents clearly understood the importance of learning especially after COVID-19. Interest on learning new skills increased post covid19. Companies also started investing and focusing on learning to develop more talents among their employees to meet the uncertain situation in the business.

Overall, majority of the respondents realised and understood the importance of learning in their career path after COVID-19. It is essential to every employees and employees to focus on learning and educate their employees to meet the uncertain business situation and face the upcoming challenges in this VUCA world. Flexibility in the manpower is one of the success factors of every organisation, also an opportunity every employee with multi skills. Life is a learning process and learning is the never-ending process of every individual to be successful in their personal and profession life. 


\section{REFERENCE}

[1] Antony Joe Raja V (2016), Effectiveness of Learning and Development, Journal of Management, Vol.3, No.1, pp.1-12.

[2] Moekti P. Soejachmoen (2016), Globalization and the Automotive Industry: Is Indonesia missing out?, Asian Economic Papers, Vol.15, No.1, pp.1-19. C 2018 JETIR December 2018, Volume 5, Issue 12 www.jetir.org (ISSN-2349-5162) JETIR1812B55 Journal of Emerging Technologies and Innovative Research (JETIR) www.jetir.org 437

[3] Priyanka Nema (2017), Transformation of Human Resource Management Practices in India after the Liberalization - A Case Of Tata Motors, International Journal of Management and Applied Science, Vol.3, No.1, pp.149-152.

[4] Rekha Mudkanna and Losarwar S.G. (2014), Learning Practices Followed by Automobile Industries, Asian Journal of Management Sciences, Vol.2, No.5, pp.18-20. 5. Saria Hassan (2016), Impact of HRM Practices on Employee's Performance, International Journal of Academic Research in Accounting, Finance and Management Sciences, Vol.6, No.1, pp.15-22.

[5] Acemoglu, D. and Restrepo, P., Artificial Intelligence, Automation and Work, Working Paper 24196, NBER Working Paper Series, National Bureau of Economic Research (2018)

[6] Hester van Breda-Verduijn, Marjoleine Heijboer, Learning culture, continuous learning, organizational learning anthropologist, Industrial and Commercial Learning, 48(3), 123-128 (2016). https://doi.org/10.1108/ICT-11-2015-0074.

[7] Haile, Getinet A., Organisational Accreditation and Worker Upskilling in Britain. IZA Discussion Paper No. 11479. Available at SSRN: https://ssrn.com/abstract=3170268.

[8] Acemoglu, D., \&Restrepo, P., The race between machine and man: Implications of technology for growth, factor shares and employment (No. w22252). National Bureau of Economic Research, (2017).

[9] Frey, C. B., \& Osborne, M. A., The Future of Employment: How Susceptible are Jobs to Computerisation? OMS Working Papers, September 18. http://www.futuretech.ox.ac.uk/sites/futuretech. ox.ac.uk/files/The_Future_of_Employment_ OMS_Working_Paper_0.pdf; short URL: http://v. gd/iViQ0L.

[10] Nwokocha, I., The Validity of Effectiveness of Learning and Development in Organizations in Nigeria, IOSR Journal of Business and Management. [Online], 17 (5), 01-08 (2015). Available from: http://iosrjournals.org/iosr-jbm/papers/Vol17-issue5/Version-2/A017520108.pdf.

[11] Walsh, K., Sturman, M.C. \& Longstreet, J., Key Issues in Strategic Human Resources. In: C. Enz (ed.). The Cornell School of Hotel Administration handbook of applied hospitality strategy [Online], CA: CA: SAGE, 394-414 (2010). Available from: http://scholarship.sha.cornell.edu/cgi/viewcontent.cgi?article=1244\& context=articles.

[12] Prabhjot Kaur, Shelley Khosla (2016), Employee Engagement in GE-International Journal of Management Research Vol. 4, Issue 12, December2016 ISSN(O): 2321-1709, ISSN(P): 23944226. Available from https://1library.net/document/zkerjkpz-employee-engagement-alluringdrift-for-executives.html\#fulltext-content 